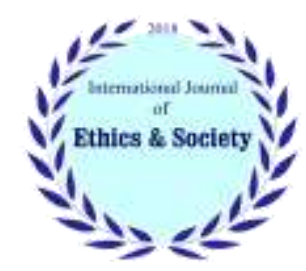

International Journal of Ethics \& Society (IJES)

Journal homepage: www.ijethics.com

Vol. 3, No. 2 (2021)

\title{
Social Capital and Environmental Ethics of Farmers
}

\author{
Richie Rianti \\ Dept. of Agriculture, Faculty of Agriculture, Gadjah Mada University, Indonesia
}

\section{Abstract}

Background: Benefiting from environmental ethics is a prerequisite for solving environmental problems. On the other hand, it seems unlikely to solve these problems without considering the social capital of society, so this study was conducted to identify environmental ethics and the impact of social capital on it.

Method: It is an applied correlation research. The statistical population of this study was all farmer, 178 of whom were selected as a statistical sample based on Bartlett table and random sampling method. A researcher made questionnaire was used to collect information. Data were analyzed by Pearson and Spearman correlation and multi-regression analysis.

Results: The results indicate that social capital and all its components are correlated with environmental ethics at the level of $0.001 \%$.

Conclusion: The results indicate that the promotion of social capital among farmers can improve environmental ethics and therefore in the end, some suggestions have been made based on this.

Keywords: Environmental ethics, Social capital, Ethics

\section{Introduction}

In recent decades, increasing demand for agricultural products for food and industrial use has made agriculture very important and thus has been named the largest industry on Earth (1). Considering that any agricultural activity harms the environment $(2,3)$. Therefore, in recent years, the problems and environmental crises resulting from these activities, which are becoming more acute day by day (4), have occupied the human mind today (5). In this regard, some experts have come to believe that the root of most environmental problems arises from ourselves (humans) (6). Many experts believe that

*Corresponding Author: Email: riantirichie@gmail.com

Received: 01Apr 2021

Accepted: 25 May 2021

36

Available at: www.ijethics.com 
environmental problems caused by human activities cannot be completely solved by the use of technology alone, and changes in human behavior are needed, and the importance of this issue is such that the direction of environmental sciences from environmental and physical sciences to Behavioral sciences are changing. Some researchers also explicitly state that environmental crises in the world today are in fact a value and moral crisis and require a moral solution (7). Although considering the root of all environmental problems as moral crises may seem pessimistic to human beings, but in general it can be said that the decline of human values, including moral values, is one of the causes of increasing environmental crises (8). Therefore, one of the proposed solutions to solve these problems is to promote ethics among individuals, especially those who are closely related to the environment. This is why the concept of environmental ethics is related to the moral relationship between man and nature (9) has been discussed in scientific forums.

Although, like many concepts, there is no consensus on environmental ethics (10) but it can be said that environmental ethics with human relationship with the environment, human knowledge of nature and sense of responsibility for it and the human obligation to set aside some natural resources for future generations, pollution, population control, it refers to resource use, energy production and consumption, wildlife protection and species diversity. In this regard, it should be noted that the relationship of individuals in any society with nature and the environment may be a completely responsible and moral approach or completely irresponsible or immoral or behavioral between the two; That this type of approach to the environment can be considered as a result of numerous variables that are mainly related to the social environment. One of these variables, which is related to the social environment and has been considered by many researchers and experts in recent decades, is social capital. In its importance, it is enough that many scientists consider society as capital and emphasize it (11). Some experts also believe that in the absence of social capital, other capitals lose their effectiveness (12). In the importance of social capital, it also states that social capital enables individuals to be able to use the resources and facilities of their community in the best possible way (13). Social capital is in fact the ability to expand social action and enrich it and in a sense is the source of social action. Social capital is a tangible form and example of an informal norm that promotes cooperation between two or more people. Accordingly, if this cooperation is used in a positive direction, it can have positive effects in solving environmental problems that generally require collective cooperation.

In this regard, the question that comes to mind is that, assuming the high importance of social capital, do social capital and morality are compatible with each other so that it can be related to environmental ethics and examine their relationship. In answer to this question, some researchers believe that the concept of social capital is a moral concept and have presented their reasons in such a way that social capital is based on the desire for another; And social capital, instead of emphasizing the individual, emphasizes the pattern of relationships between individuals and originates from within these relationships, so it can easily be considered a moral concept (14) also considers social capital as a kind of ethics and considers it ethical to have an advantage and states that it is known by the hidden angles of social capital.

Given the answer to this question, it seems logical to study the relationship between social capital and environmental ethics, which is a branch of ethics. Therefore, the main purpose of this study is to investigate the relationship between these variables. The study of this issue is also very important because the review of research literature shows that despite the existence of many studies on the relationship between social capital and environmental issues, its relationship with environmental ethics is itself a value It has not been confirmed on the values of the individual and naturally on their attitude towards the environment and ultimately on their behavior towards the environment. In this regard, researcher also points to the lack of empirical studies in this regard (15). However, a narrow view of the confirmed relationship between social capital and environmental behavior can be somewhat indicative of the relationship between these variables; because your behavior can be moral or immoral. 
Considering that farmers interact more directly and interact with the environment than other groups (16) Therefore, understanding their environmental ethics is very important because of the impact of their environmental ethics on their behavior and thus the impact of their behavior on increasing or decreasing environmental crises and problems. Therefore, the present study was conducted in this region of the country. In line with the main purpose of the research, which is to investigate the relationship between social capital and environmental ethics of farmers, the following sub-objectives are also pursued:

- Investigating the amount of social capital of the studied farmers

- Study of environmental ethics of studied farmers

- Investigating the role of social capital in explaining the environmental ethics of the respondents

\section{Material \& Methods}

In terms of purpose, the research was an applied survey and in terms of data collection it was descriptive-correlation survey. The statistical population of this study included all farmers who were engaged in agricultural activities in the 2018-2019 crop year $(\mathrm{N}=8300)$. The sample size was determined using Bartlett table of 119 people and finally the confidence increase of 178 agricultural operators was studied. In the present study, simple random sampling method was used for sampling. The research instrument was a questionnaire consisting of three sections, including personal and professional characteristics (age, agricultural work experience, household size, and literacy level), Social Capital Inventory, and a section that assessed farmers' environmental ethics.

The Social Capital Questionnaire consists of 31 items. This questionnaire is taken from the American Social Capital Association, World Bank and Australian Institute of Family Studies questionnaires that assess three structural (13 questions), communication (9 questions) and cognitive (9 questions) dimensions of social capital. The structural dimension includes structural links, activities, and how teamwork is organized in the community. The communication dimension refers to the interactions and communication of members within a group and outside the group. In this dimension, indicators such as trust and mutual communication are discussed. The cognitive dimension is also related to the participation, trust, attitudes and commitments in the collection and its axis is cognition, which provides a common vision of goals and values for members by using common language. The questions in this section are scored on a Likert scale with a four-choice spectrum and in a very low to very high order from 1 to 4 , respectively. Based on this, each person can get a score between 31 and 124. A higher score indicates that the person's social capital is high.

The Environmental Ethics Questionnaire had 29 items that were scored on a Likert scale from strongly disagree to strongly agree from one to five, respectively. Based on this, each person gets a score between 145-29. A high score indicates that the person has a more favorable environmental ethic.

The face and content validity of the various sections of the measurement tool was confirmed by a number of faculty members of agricultural extension and education and experts in the field of ethics. Studies confirm that the social capital questionnaire has acceptable reliability $(\alpha<0.77)$. Accordingly, in order to confirm the reliability of the Social Capital Questionnaire and to determine the reliability of the Environmental Ethics Questionnaire in the present study, a pioneering survey was conducted using 30 farmers outside the study sample. Social and environmental ethics were 0.89 and 0.86 , respectively. To measure the environmental ethics and social capital of the respondents and group them in terms of undesirable, relatively desirable and desirable levels, the difference of standard deviation.

Descriptive and inferential statistical methods such as frequency, percentage, mean, correlation tests and regression analysis were used to analyze the data. 


\section{Results}

Descriptive statistics showed that the average age of the respondents was 46 years with a standard deviation of 12 years, with a range of 51 years with a minimum of 20 and a maximum of 71 years. The average agricultural work experience of the respondents is 21 years with a standard deviation of 11 years and a minimum and a maximum of 4 and 50 years. The average land area of the respondents is 3.32 hectares and the average number of household members of the studied farmers is 5 people. In terms of literacy level, $41.6 \%$ (74 people) of illiterate respondents, $23.6 \%$ (42 people) literate, $24.7 \%$ (44) have a cycle, $4.5 \%$ have a diploma (8 people) and 5.6\% (10 people) are above the diploma.
The frequency distribution of the respondents according to the level of social capital benefit is shown in Table (1). As can be seen in the table above, social capital is $29.2 \%$ of the respondents unfavorable and the rest is desirable and relatively desirable. Also, the results of Table 1 show that the respondents are weaker in the relational dimension of social capital than other dimensions and the percentage of weakness reaches more than $38 \%$. A subtle point that can be seen in Table 1 is that despite the weakness of most respondents in the dimension of social capital relations, more than $37 \%$ of them have a favorable situation in this dimension, which is more favorable than other dimensions.

Table 1: Frequency distribution of respondents according to the benefit of social capital
\begin{tabular}{|l|l|l|l|}
\hline Social capital components & Percentage \\
\cline { 2 - 4 } & Satisfied & Relatively satisfied & Unsatisfied \\
\hline Constructure dimension & 29.2 & 43.8 & 27.00 \\
\hline Relational dimension & 37.1 & 24.7 & 38.2 \\
\hline Cognitive dimension & 29.2 & 42.7 & 28.1 \\
\hline Social capital & 31.5 & 29.3 & 29.2 \\
\hline
\end{tabular}

According to the obtained score, farmers' environmental ethics were also classified into three groups: favorable, relatively favorable and unfavorable. According to the obtained results, the percentage of frequency of each class was as follows: desirable class $31.5 \%$, relatively desirable class $33.7 \%$ and unfavorable class $34.8 \%$. Thus, about one third of the studied farmers are in the unfavorable category in terms of benefiting from environmental ethics. The frequency distribution of farmers' environmental ethics by each class is shown in Table 2.

Table 3 shows the ranking of items in the Environmental Ethics Questionnaire based on the average. An average of 4.72 out of 5 in the statement "preservation of the environment is a divine duty." Indicates that in this case, the farmers studied had the most agreement. Similarly, an average of 2.11 in the statement "environmental protection is the duty of the government and we have no duty in this case" indicates that in this statement the farmers had the least agreement. Considering that the latter item is a item with a negative orientation and only considers the protection of the environment as the duty of governments, and therefore the disagreement of farmers in this item can be a sign of their observance of environmental ethics.

Table 2: Frequency distribution of respondents based on environmental ethics

\begin{tabular}{|l|l|l|l|}
\hline & Frequency & FC & FC\% \\
\hline Unsatisfied & 62 & 34.8 & 34.5 \\
\hline $\begin{array}{l}\text { Relatively } \\
\text { satisfied }\end{array}$ & 60 & 33.7 & 68.5 \\
\hline Satisfied & 56 & 31.5 & 100 \\
\hline Total & 178 & 100 & \\
\hline
\end{tabular}




\section{Table 3: Status of environmental ethics of the studied farmers}

\begin{tabular}{|c|c|c|c|c|c|}
\hline & Question & Mean & SD & CV & Rank \\
\hline 1 & $\begin{array}{l}\text { If we humans damage the environment in our own place, we will see the result } \\
\text { elsewhere. }\end{array}$ & 4.45 & 0.69 & 0.155 & 8 \\
\hline 2 & The environment should only be preserved when it is economically profitable. & 2.84 & 1.42 & 0.5 & 29 \\
\hline 3 & The nature in which we live is created by God, so it must be respected. & 4.71 & 0.72 & 0.153 & 2 \\
\hline 4 & $\begin{array}{l}\text { The use of chemical fertilizers on the farm is necessary for further production and } \\
\text { is not harmful to the environment. }\end{array}$ & 3.43 & 1.47 & 0.429 & 25 \\
\hline 5 & The environment has been entrusted to man by God. & 4.64 & 0.56 & 0.121 & 3 \\
\hline 6 & $\begin{array}{l}\text { The industrialization and consumerism of human beings has caused damage to the } \\
\text { environment. }\end{array}$ & 3.87 & 1.10 & 0.284 & 23 \\
\hline 7 & $\begin{array}{l}\text { Pesticides are needed to produce more produce on the farm and are not harmful } \\
\text { to the environment. }\end{array}$ & 3.30 & 1.35 & 0.409 & 26 \\
\hline 8 & $\begin{array}{l}\text { Instead of fossil fuels polluting the environment, human beings should use ener- } \\
\text { gies such as wind, sun, etc. }\end{array}$ & 4.16 & 0.82 & 0.197 & 17 \\
\hline 9 & Preserving the environment is a divine duty. & 4.72 & 0.5 & 0.106 & 1 \\
\hline 10 & $\begin{array}{l}\text { To preserve the environment, humans must change their consumption patterns (in } \\
\text { terms of fuel, energy and resources). }\end{array}$ & 3.98 & 0.77 & 0.193 & 21 \\
\hline 11 & $\begin{array}{l}\text { Man has no choice but to pollute the environment to achieve prosperity and com- } \\
\text { fort. }\end{array}$ & 2.92 & 1.44 & 0.493 & 27 \\
\hline 12 & $\begin{array}{l}\text { The government must make laws to protect the environment and require people } \\
\text { to abide by them. }\end{array}$ & 3.57 & 1.14 & 0.319 & 24 \\
\hline 13 & If we use the wrong environment, we have betrayed God's trust. & 4.38 & 0.80 & 0.183 & 11 \\
\hline 14 & $\begin{array}{l}\text { Occurrence of natural disasters such as floods, storms, etc. is the result of human } \\
\text { damage to the environment. }\end{array}$ & 4.05 & 0.93 & 0.230 & 20 \\
\hline 15 & We must not endanger others by destroying the environment, even if it is small. & 4.16 & 0.73 & 0.175 & 16 \\
\hline 16 & Harm to the environment is bad, even if it has benefits. & 4.13 & 0.75 & 0.182 & 18 \\
\hline 17 & Humans should not treat the environment in a way that harms other humans. & 4.37 & 0.73 & 0.167 & 12 \\
\hline 18 & $\begin{array}{l}\text { We all need to make sure that what we do does not cause the slightest harm to the } \\
\text { environment. }\end{array}$ & 4.43 & 0.73 & 0.165 & 10 \\
\hline 19 & $\begin{array}{l}\text { It is necessary to have a moral charter in the field of environmental protection of } \\
\text { the country that everyone is aware of. }\end{array}$ & 4.06 & 0.83 & 0.204 & 19 \\
\hline 20 & $\begin{array}{l}\text { The benefits of environmental protection may not be apparent today, but our chil- } \\
\text { dren will benefit from them in the future. }\end{array}$ & 4.26 & 0.74 & 0.174 & 14 \\
\hline 21 & Man must preserve the environment, even if it does not benefit him. & 4.31 & 0.61 & 0.142 & 13 \\
\hline 22 & $\begin{array}{l}\text { We must preserve the environment even if we have to use our own personal capital } \\
\text { to do so. }\end{array}$ & 3.95 & 0.94 & 0.238 & 22 \\
\hline 23 & $\begin{array}{l}\text { Protecting the environment is the duty of the government and we have no duty in } \\
\text { this regard. }\end{array}$ & 2.11 & 1.00 & 0.474 & 29 \\
\hline 24 & Man is responsible for protecting the environment. & 4.21 & 0.68 & 0.162 & 15 \\
\hline 25 & We must pass on a healthy environment to future generations. & 4.47 & 0.66 & 0.148 & 4 \\
\hline 26 & We must not harm the environment, but we must use it. & 4.45 & 0.58 & 0.130 & 7 \\
\hline 27 & Although we have control over the environment, we need to take good care of it. & 4.45 & 0.54 & 0.121 & 6 \\
\hline 28 & We must protect living things, especially living things that are good for humans. & 4.47 & 0.67 & 0.150 & 5 \\
\hline 29 & $\begin{array}{l}\text { Man must have a friendly relationship with the environment, like the relationship } \\
\text { he has with his friends. }\end{array}$ & 4.44 & 0.63 & 0.142 & 9 \\
\hline
\end{tabular}

Pearson correlation coefficient was used to investigate the relationship between social capital and environmental ethics (Table 4). The results of the table in question indicate that social capital and all its components have a significant relationship at the level of $0.001 \%$ with the environmental ethics of farmers, which is a stronger cognitive component than the other two components. The results also indicate that environmental ethics is inversely related to household size, land area of respondents and their agricultural history (Table 4). The table also confirms that the two variables of age and literacy level are not significantly related to farmers' environmental ethics. 


Table 4: Correlation of research variables and
environmental ethics of the studied farmers
\begin{tabular}{|l|l|l|l|}
\hline Component & R & Sig. & Test \\
\hline Social capital & 0.000 & $0.34^{* * *}$ & Pearson \\
\hline Cognitive & 0.000 & $0.34^{* * *}$ & Pearson \\
\hline Structural & 0.000 & $0.32^{* * *}$ & Pearson \\
\hline Relational & 0.000 & $0.29^{* * *}$ & Pearson \\
\hline Age & 0.08 & 0.13 & Pearson \\
\hline Familial & 0.02 & $-0.17^{*}$ & Pearson \\
\hline Land area & 0.02 & $-0.17^{*}$ & Pearson \\
\hline $\begin{array}{l}\text { Agricultural } \\
\text { history }\end{array}$ & 0.000 & $-0.30^{* *}$ & Pearson \\
\hline literacy & 0.23 & -0.08 & Spearman \\
\hline $\begin{array}{l}* \text { Significance at the level of } 0.05 \% \\
* * \text { Significance at the level of } 0.01 \% \\
\text { *** Significance at the level of } 0.001 \%\end{array}$ \\
\hline
\end{tabular}

Stepwise multiple regression was used to investigate the effect of social capital components on the dependent variable of environmental ethics of respondents. For this purpose, social capital components (cognitive, communication, structural) were used in regression analysis. According to the results of Table 6, the F-level of ANOVA test was significant at the level of $1 \%$, which indicates the existence of a relationship between predictor variables and dependent variables. Based on beta values, only the cognitive component has an effect on the variable of farmers' environmental ethics, and for one standard deviation of change in this variable, we will see 0.34 standard deviation of change in the dependent variable; That is, the coefficient of effectiveness of the cognitive component $(\beta=0.34)$ shows that this component can predict changes in the level of environmental ethics of farmers, so that more cognitive dimension of social capital will increase the environmental ethics of respondents, vice versa. Based on the adjusted R2, the cognitive component is able to predict $11 \%$ of the changes in the dependent variable.

\section{Table 5: Summary of stepwise regression analysis information for dependent variable of farmers' environmental ethics

\begin{tabular}{|l|l|l|l|l|l|}
\hline Component & B & SEB & Beta & T & Sig. \\
\hline Cognitive & 0.79 & 0.16 & 0.34 & 4.77 & 0.000 \\
\hline Multiple R=34/0, R2 $=12 / 0$, R2 Adjust $=11 / 0$, Constant $=63 / 90, \mathrm{~F}=71 / 22$, Sig. $\mathrm{F}=000 / 0$ &
\end{tabular}

\section{Discussion}

The results of the research showed that the environmental ethics of most of the studied farmers is favorable and relatively desirable. The results of popular studies largely confirm this result. Considering that the adherence or non-adherence of individuals to their environmental ethics is affected by many factors such as facilities, attitude, knowledge; therefore, the country's environmental officials and parents should try to maintain environmental ethics in the current situation by providing environmental knowledge, etc., and considering that moral action requires education (17), it seems. Increasing moral education in various ways, especially through religious education, can make the current situation more favorable. The results showed that there is a direct relationship between all components of social capital (communication, structural and cognitive) and environmental ethics. Therefore, it can be said that the stronger the structural links and interactions, the more cooperation between people.

In general, the research results showed that social capital and environmental ethics have a direct relationship. This means that people with higher social capital have more favorable environmental ethics. The results of studies, which show that social capital is related to the management and conservation of biodiversity, which is a subset of environmental ethics, confirm this result $(18,19)$. The study also showed that there is a relationship between social capital and environmentally responsible behaviors (20). It can be said that people with high social capital try to get information about how to deal with the environment, and this effort ultimately leads to the improvement of their environmental ethics. 
On the other hand, ethical rules influence individual and collective behaviors (21). Accordingly, these rules, which have been developed for example in environmental ethics, form reference frameworks that determine human behavior when interacting with the environment (22). Accordingly, the environmental ethics to which one adheres compels one to form networks of communication between friends, neighbors, and other members of society based on commitment and trust in order to protect the environment or better interact with nature. These connections, called social capital by experts, ultimately spread the rules and opinions of environmental ethics among members of society. Therefore, in general, it can be said that environmental ethics and social capital have a two-way relationship, each of which strengthens the other. The results of the research also indicate that environmental ethics is independent of age and literacy levels. This means that; Environmental ethics of young, middle-aged and old farmers with any level of literacy is not significantly different from each other. The results of these studies are consistent with other studies $(21,23)$.

The results also indicate that the household dimension is inversely related to the environmental ethics of the respondents. This means that with the increase of the household dimension, the level of environmental ethics of the respondent's decreases. In this regard, it should be noted that increasing the household dimension increases household costs and this issue causes people to comply with environmental ethics in order to provide lower living costs.

At the end of the discussion, it should be noted that the interpretation of the results of the present study should be done taking into account the limitation that this study was conducted in a specific area and therefore generalizing the results to farmers in other parts of the country should be done with caution.

\section{Conclusion}

In general, the results of the present study indicate that the environmental ethics of most of the farmers studied are favorable and relatively desirable. Also, social capital and all its components (cognitive, communicative, and structural) are directly related to environmental ethics; therefore, it can be concluded that in order to promote the environmental ethics of farmers, social capital and its components should be strengthened. Of course, it should be noted that social capital is only one of the factors related to environmental ethics

\section{Ethical Consideration}

Ethical issues (such as plagiarism, conscious satisfaction, misleading, making and or forging data, publishing or sending to two places, redundancy and etc.) have been fully considered by the writers.

\section{Acknowledgement}

Researchers consider it necessary to thank and appreciate all the participants who helped us in this research.

\section{References}

1. Clay J (2013). World agriculture and the environment: a commodityby-commodity guide to impacts and practices. Island Press, Washington, D.C. / USA.

2. Sinha H (2006). People and forest: unfolding the participation mystique. Concept Publishing Company, New Delhi/ India.

3. Paarlberg R (2009) the ethics of modern agriculture. Society, 46(1): 48 .

4. Osbaldiston R, Schott JP (2011). Environmental sustainability and behavioral science: Meta-analysis of pro environmental behavior experiments. Environment \& Behavior, 44(2): 257-299.

5. Miller A (2013). Environmental problem solwing: psychosocial barriers to adaptive change. Springer, New York/USA.

6. Fabinyi M (2011). Fisbing for fairness: poverty, morality and marine resource regulation in the Philippines. ANU E Press, Canberra/Australia.

7. Taylor PW (2011). Respect for nature: a theory of environmental ethics. Princeton University Press, USA.

8. Weston A (2009). The incomplete eco-philosopher: essays from the edges of environmental ethics. SUNY Press, New York/USA . 
9. Pretty J, Smith D (2004). Social capital in biodiversity conservation and management. Conservation Biology, 18(3): 631638.

10. Pretty J, Ward H (2001). Social capital and the environment. World Development, 29(2): 209-227.

11. Onyx J, Bullen P (2000). Measuring social capital in five communities. The Journal of Applied Behavioral Science, 36(1): 23-42.

12. Jones N, Sophoulis CM, Iosifides T, Botetzagias I, Evangelinos K (2009). The influence of social capital on environmental policy instruments. Environmental Politics, 18(4): 595-611.

13. Illingworth P (2012). Ethics and social capital for global well-being. International Review of Economics, 59(4): 389-407.

14. Gangadharappa V, Pramod T, Shiva H (2007) Gastric floating drug delivery systems: A review. Indian J Pharm Ed Res, 41(4): 295-305.

15. Hatcher T (2004). Environmental ethics as an alternative for evaluation theory in for-profit business contexts. Evaluation and Program Planning, 27(3): 357-363.

16. Corral-Verdugo VC, Bechtel RB, Fraijo-Sing B (2003). Environmental beliefs and water conservation: An empirical study. Journal of Environmental Psychology, 23(3): 247-257.
17. Crane A (1999). Are you ethical? Please tick yes or no on researching ethics in business organizations. Journal of Business Ethics, 20(3): 237-248.

18. Adler PS, Kwon SW (2002). Social capital: Prospects for a new concept. Academy of Management Review, 27(1): 17-40.

19. Ayios A, Jeurissen R, Manning P, Spence LJ (2014). Social Capital: A review from an ethics perspective. Business Ethics: A European Review, 23(1): 108-124.

20. Hester RE, Harrison RM (2012). Emironmental impacts of modern agriculture: royal society of chemistry. Royal Society of Chemistry, UK.

21. Pretty J, Ward H (2001). Social capital and the environment. World Development, 29: 209-227.

22. De Korm MP (2017). Farmer participation in agri-environmental schemes: Regionalization and the role of bridging social capital. Land Use Poligy, 60: 352-361.

23. McGrath F, Erbaugh J, Leimona B, Amaruzaman S, Rahadian N, Carrasco L (2018). Green without envy: How social capital alleviates tensions from a Payments for Ecosystem Services (PES) program in Indonesia. Ecology and Society, 23(4). 